\title{
Supporting Stimulation Needs in Dementia Care through Wall-Sized Displays
}

\author{
Corina Sas ${ }^{1}$, Nigel Davies ${ }^{1}$, Sarah $_{\text {Clinch }}{ }^{2}$, Peter Shaw $^{1}$, Mateusz Mikusz ${ }^{1}$, \\ Madeleine Steeds ${ }^{2}$, Lukas Nohrer ${ }^{2}$ \\ ${ }^{1}$ Lancaster University, U.K., and ${ }^{2}$ University of Manchester, U.K. \\ ${ }^{1}$ \{forename-initial\}.\{surname\}@lancaster.ac.uk, 2 f forename\}.\{ surname\}@ manchester.ac.uk
}

\begin{abstract}
Beside reminiscing, the increasing cognitive decline in dementia can also be addressed through sensory stimulation allowing the immediate, nonverbal engagement with the world through one's senses. Much HCI work has prioritized cognitive stimulation for reminiscing or personhood often on small screens, while less research has explored sensory stimulation like the one enabled by large displays. We describe a year-long deployment in a residential care home of a wall-sized display, and explored its domestication through 24 contextual interviews. Findings indicate strong engagement and attachment to the display which has inspired four psychosocial interventions using online generic content. We discuss the value of these findings for personhood through residents' exercise of choices, the tension between generic/personal content and its public/private use, the importance of participatory research approach to domestication, and the infrastructure-based prototype, illustrated by the DementiaWall and its generative quality.
\end{abstract}

\section{Author Keywords}

Dementia; psychosocial informal interventions; wall-sized displays; stimulation; memory technologies; reminiscing.

\section{CCS Concepts}

-Human-centered computing $\rightarrow$ Human computer interaction; Field studies; Ubiquitous and mobile computing;

\section{INTRODUCTION}

Dementia is a progressive syndrome impairing cognitive functions alongside sensory loss, deterioration of emotion regulation or social behavior, and represents the major cause of dependency in older adults [1]. The WHO [68] report that almost 50 million people worldwide live with dementia, a number that is expected to double every two decades. In addition to pharmacological interventions, studies have shown complementary value in psychosocial ones, particularly in care homes where residents are likely to benefit from increased stimulation [51]. The need for stimulation in dementia is also supported by

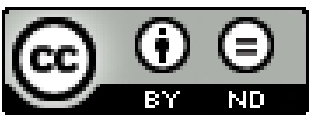

This work is licensed under a Creative Commons Attribution-NoDerivs International 4.0 License.

CHI '20, April 25-30, 2020, Honolulu, HI, USA.

(C) 2020 Copyright is held by the owner/author(s).

ACM ISBN 978-1-4503-6708-0/20/04.

http://dx.doi.org/3313831.3376361

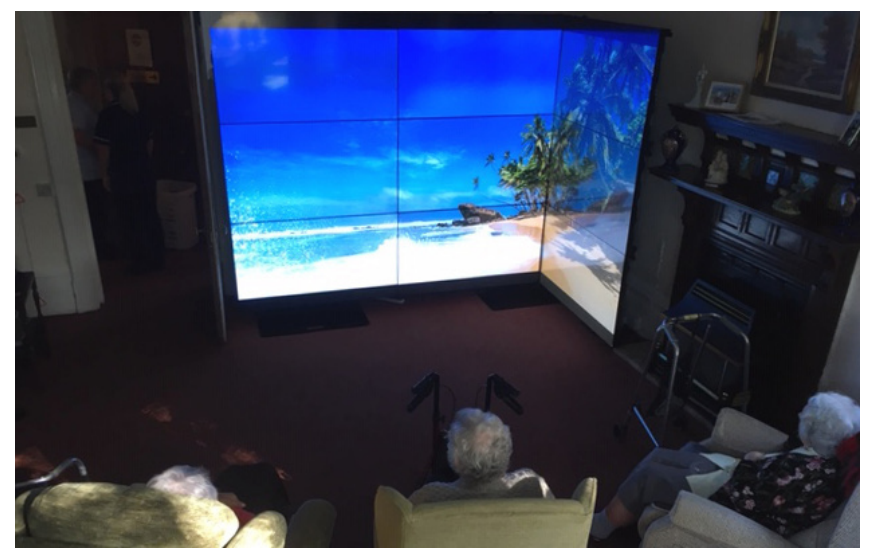

Figure 1: The DementiaWall showing a video of seascape with gently breaking waves as part of a novel nature-inspired psychosocial intervention (Photo: CPaul Rowley)

the retrogenesis process [79] indicating that the degenerative stages of dementia map key aspects of Piaget's developmental stages [72] albeit in reverse order. Reviews of psychosocial interventions indicate the effectiveness of person-centered care through social contact [16, 59]; recreational [100], and relaxation activities [16], and in particular cognitive [100] and sensory stimulation [16, 59, 100] through music [107] and light therapy [107], somatic practices [107, 59] or multisensory interventions [59]. In addition to emotional benefits, psychosocial interventions also mitigate behavioral symptoms of dementia such as agitation or wandering [107].

The significant costs of dementia care have also led to a growing interest in the development of technologies, from assistive ones extending independent living and aging in place [90, $114]$ to memory technologies $[41,57,91,105,122]$. Much of this work leverages communication, tangible, or tracking technologies but less so wall-sized displays. We argue that such displays offer stimulation affordances for an increased sense of presence, immersion, arousal, memory and enjoyment $[13,60,78,80,92]$ whose value for supporting stimulation in dementia care may be particularly useful to explore. The advances of HCI research on large displays [21, 82, 108, 109] coupled with the state-of-the-art of these technologies are now ripe to be exploited for robust deployment in sensitive settings like dementia care homes. This work aims to explore the fea- 
sibility and domestication of the DementiaWall, a wall-sized display deployed for one year in a residential care home to inspire novel informal psychosocial interventions. This was explored through observation, contextual interviews and analysis of logged usage data. To achieve this aim, we focused on three research questions:

(i) How do wall-sized displays become domesticated or integrated in residential care homes and their residents' lives?

(ii) What types of media content is relevant for such displays?

(iii) What informal psychosocial interventions do they inspire?

The main contributions of this work include (i) fresh understandings of how domestication of this technology takes place in sensitive settings; (ii) novel psychosocial interventions leveraging the wall-sized displays' affordances; and (iii) infrastructure-based prototype as a new way to uncover needs in sensitive settings, involving the decoupling of display's hardware and software from its media content.

\section{RELATED WORK}

Our research draws on prior work on the application of HCI to aging and dementia, particularly in sensitive settings, and on the use of large displays. The intersection of these domains has received little attention to date.

\section{$\mathrm{HCl}$ Research on Aging and Dementia}

HCI research in this space has focused broadly on supporting memory and reminiscing, social communication, and sense of identity of older people. A wealth of HCI work has looked into the value of digital memory cues enabled by technologies such as lifelogging [41, 101], photos [91, 101], videos [56], ambient displays [23], or tangible artifacts [71, 112] for remembering [113] or forgetting [96, 98]. Most research has focused on adults' personal or family memory archives, with less work exploring memories of older people. A noticeable exception is work on the wearable SenseCam, showing its value for older people experiencing memory impairment [41, 57]. Additional research for supporting older people's reminiscence includes tangible objects such as Living Memory Box [105] or digitally augmented scrapbooks like Memento [122]. Apart from cuing autobiographical memories in general, other work has started to explore how people can craft such cues [99, 91] for autobiographical memories, as well as for self-defining ones playing a key role in personhood [89].

Another relevant HCI area has focused on supporting older people's need to share stories. The sharing of personal stories $[20,53]$ has been explored through digital collages such as Multimedia Biographies [20], and ambient displays showing life review and SenseCam's photos [20]. Insights from these systems indicate that besides its emotional benefits, sharing stories with loved ones also supports reminiscing and strengthens the sense of self $[20,49]$. A specific body of HCI work has begun to explore the construct of personhood, and how people with dementia can be involved in co-design through craft or art $[117,55,54]$. For instance, Crabtree et al. employed a variant of cultural probes to explore the needs of people living in care settings [19], while Wallace et al. [118] developed design probes to co-design digital jewelry with people living with dementia, which in turn supported their sense of self, reminiscing, and social relationships with loved ones.

\section{$\mathrm{HCl}$ Research on Dementia in Sensitive Settings}

Outside of older people's own homes (i.e., for independent living), sensitive settings [119] such as hospitals [117], hospices [95], or care homes $[55,58,66]$ have received limited attention. Exceptions include Portrait [120], a touchscreen interface exploring personal interests of people living with dementia to support staff in care home engage in personalized conversations. The distinction between such personally-relevant, and generic reminiscing material has been explicitly made, for example in CIRCA [2], a touchscreen interface providing generic multimedia content under themes of recreation, entertainment and local history. Their findings indicate that the value of generic content relies on its ability to stimulate personal memories, while follow-up work exploring both personal and generic content has shown users' preference for the former [87]. Personal content however can be difficult to source in care home settings so that online content sourced from YouTube or Wikipedia to reflect residents' personal interests has been found to be also cognitively stimulating, albeit difficult to see on small screens [3]. While institutional settings offer ample opportunities for group-based interventions, these have been less explored in HCI [3]. One exception focuses on group reminiscing therapy [123] for social interaction and cognitive stimulation [104] consisting of videos shown on a large flat screen, informed by patients' interests and sourced from YouTube, that contributed to increased wellbeing, communication and engagement [69]. Research on dementia and associated sensory loss in the ability to detect movement, colors and contrast, or for peripheral vision [6] has shown the value of multisensory, embodied experiences $[15,61]$ and of understanding subtle ways in which people with dementia engage [54] for instance with music [66, 81].

\section{Large \& Public Displays: Experience and Engagement}

The inclusion of digital displays as part of our everyday surroundings, predicted in Weiser's early visions of ubiquitous computing [121], has become a reality impacting significantly users' experience and engagement. Large displays as desktop monitors have been shown to impact task performance $[82,21]$ due to peripheral awareness [21], and immersion [108, 109]. In contrast, the deployment of public displays has been shown to support a larger range of functions from social communication and awareness to civic engagement, by addressing the needs of passive or active engagement and discovery, already afforded by public spaces [65].

However, public displays that are shared for public viewing of media content differ fundamentally from private devices in their broader interaction models [27, 28, 52], raising interesting issues regarding adoption and attachment [22]. Indeed, despite these benefits, findings on public displays have consistently shown limited user engagement $[12,46]$ and adoption [14]. In their review of the challenges associated with large displays, Huang et al. [46] identified their size (which demands novel interactions) and their public nature (no personal ownership, public audience) as key. They suggested addressing these challenges through the provision of evident user value, 
support for different functions, easy interaction and ability to observe others, as well as through champions for engagement. Even when engagement is identified, its duration matters. In their review of novelty effect of large displays' deployment, Kock et al. [50] made the distinction between initial novelty immediately following deployment, and recurring novelty due to follow-up changes. They suggest that the former can last between 1 and 6 months, while the latter may last several weeks, and that the duration of the novelty effect depends on two set of factors pertaining to users such as skills, intrinsic motivation to use, relevance to their activity, number of users and their frequency of use; and pertaining to follow-up changes such as magnitude and frequency of change, presentation of content, ways of capturing attention, and collaborative development.

The impact of large screens on user's experience has also been explored mostly in media research indicating increased attention and arousal $[13,75,76,26]$ due to the novelty of images appearing closer or larger than in real life, and even more so if movement is involved [75]. Screen size can both elicit and regulate arousal, with small screens supporting calming down [75]. In contrast, larger screens lead to increased arousal, often associated with better memory recall $[78,96]$, embodiment [7], enjoyment [60, 77, 80] particularly when the displayed content is favored [60], immersion (as the degree to which mediated information dominates viewers' senses and attention), and sense of presence (or viewers' becoming absorbed in the mediated narrative, feeling present in its world) [34, 88, 93].

To conclude, to date, HCI work has largely focused on support for reminiscing, social communication, and sense of identity, predominantly in home settings, with personally relevant content shown on touchscreens. Despite findings indicating that viewing of personal content on small screens can be problematic in cognitive stimulation activities such as group reminiscing in dementia care homes $[48,81]$, large displays have received limited use in these settings.

\section{CONTEXT}

Our project took place in a family-own residential care home in an English town. It is located in a Victorian house with three large rooms for social activities and surrounding small gardens offering award winning personalized care to its residents. As described by one participant it is like: "the Best Western country hotel; it hasn't got really a care home feel; [but more] like you could be coming to somebody's lounge, or when you go up the stairs it's like you have been in a hotel" [F4]. The home provides care to up to 25 female residents, 21 when the study started, most older than eighty years and who could no longer live independently. Each resident has her own private room where they are surrounded by familiar objects mostly photos, household items, or small pieces of furniture.

The three large rooms on the ground floors are where most residents spend their days. The largest room is furnished with dining tables and chairs throughout, as well as armchairs near the windows, serving both dining and activity functions. The space is configured to allow for easy movement as wheelchairs are used by a few residents. This room does not have TV but benefits from a radio and media player, and also has a small fish tank. The second room is smaller, furnished as a seating room with a TV which is seldom watched as residents and their visitors prefer to use this room for intimate conversations. The third room is longer and partly darker, furnished with chairs and armchairs placed around its perimeter.

With respect to daily routines, the three main meals are served at fixed times with snacks being offered throughout the day. Residents are given the option of choosing their meal from a menu. There are at least two structured activities each day such as group reminiscing or crafts, one in the morning and one in the afternoon, as well as informal ones such as one-to-one reminiscing as needed by residents. In small numbers, residents are supported to join the food preparation in the kitchen, and sometimes helped to prepare food from their own cultural heritage. Residents are also assisted to take short trips to the town or the local church. When activities are not conducted, residents tend to sit, have occasional small conversations, or fall asleep. The level of energy in the main room is often regulated by the care staff through music. A chaplain visits once per week providing mass and additional pastoral care, and the residents also benefit from weekly hairdressing services. After dinner, most residents go to their rooms while during the night, a nurse checks on the well-being of each resident.

\section{METHODOLOGY}

The aim of our work is to explore the feasibility of wall-sized displays for dementia care in a residential home. The specific affordances of large displays for increased enjoyment [60, $77,80]$, arousal [13, 26, 76, 75], memory [78], immersion and sense of presence [34, 60, 80, 88, 93], and for regulating arousal [75] offer untapped potential to address sensorial loss and limited stimulation in dementia. Large displays could also support reminiscing, through both generic [2] and personally relevant content $[3,69]$. Apart from the above rationale, our project also builds on the owners' strong interest in experimenting and adopting novel technologies to improve their provision of care. Prior to this project, they collaborated with a university to create a tablet-based technology similar to Portrait [120] whereby residents' profiles and interests were shared to support care staff engage in personalized conversations.

These considerations have led to the design and deployment of the DementiaWall, a wall-sized display that could be used to show both generic and personalized content, and therefore to inform the co-design of informal interventions for sensory stimulation and collective reminiscing. While we initially framed our research as researcher-led, what we have noticed was that this was gradually reshaped, taking on aspects of participatory design and research [70]. This was reflected in owners' and care staff's enthusiasm to employ their professional expertise in order to source online content for residents' needs. This shift provided us the opportunity to explore these emerging practices around the DementiaWall, and by adopting the tenets of participatory research, as researchers we contributed to the co-design of interventions albeit by deliberately supporting the care staff leading it instead of leading ourselves.

The DementiaWall shares similarities with ubiquitous prototypes such as public displays which through their complex large scale infrastructure and long term deployment [84, 62] for continuous use [24] are radically different than prototypes 
of personal technologies. However, while ubiquitous prototypes require continuous provision of high quality content which researchers are challenged to generate and curate [106], the DementiaWall differs through its ability to decouple the hardware/software infrastructure from the media content. In turn, this allowed the decoupling of expertise: technical competency required for setting up and maintaining it, and care staff's skills for sourcing online content in order to design and deliver interventions. We call this prototype an infrastructurebased prototype and explored its qualities.

\section{DementiaWall: System Description}

The DementiaWall prototype comprises of nine high quality screens designed for near-continuous operation with wide viewing angles, custom trussing, a Windows 10 computer, stereo speaker system, and a wireless keyboard with track-pad. Each screen is daisy chained and configured so the computer can treat them as one screen output. The screens (each $121 \mathrm{~cm}$ $\mathrm{x} 68 \mathrm{~cm}$ ) are arranged in a $3 \times 3$ grid with the rightmost column placed perpendicular to the others, creating an ' $L$ ' shape [Figure 1]. The longest edge is therefore $242 \mathrm{~cm}$ wide and the shorter $121 \mathrm{~cm}$; the height of the display is $204 \mathrm{~cm}$. Because the DementiaWall was a bespoke and unfamiliar platform for staff, we provided a familiar interface for interacting with it: a standard Google Chrome web browser installed. The data on the use of the DementiaWall was captured through a system logger, namely the use of web-content and any other applications such as Windows Media Player.

\section{Longitudinal Study}

The study took place over a year-long deployment throughout which the research team engaged in regular, quarterly visits. The system has been left in the care home to continue the relationship with its staff, residents and family members. Given the vulnerability of their users, in such sensitive settings it is imperative to not rush into the deployment of novel technologies [19]. Therefore, before deployment, we had extensive conversations with the owners, who are both managers and care staff, regarding the displays' size, shape, and placement.

The study consisted of ethnographic observation and semistructured interviews to explore the use and experience of the wall-sized display, the psychosocial interventions it inspired, their perceived benefits, and ways in which the display has impacted on the care homes' routines and practices. Throughout the study, we interviewed 24 participants: nine interviews included twelve family members [F1-F12] ( 9 adult children, 3 adult children-in-law; 8 female, 4 male); eleven were conducted with staff [S1-S11] (5 female, 6 male), and one with a resident who was able to provide informed consent [R1]. Interview analysis was completed using Atlas/ti software [35] which led to 662 quotes being associated to 505 codes refined down to 31 thematic concepts through a hybrid approach of coding and theme development [31]. Informed by prior work we developed a conceptual framework that provided initial codes, namely types of psychosocial interventions such as those supporting the need for stimulation, role of technology for group reminiscing, social communication and personhood, generic and personal content. This was refined from interview data as new codes emerged on the specific categories

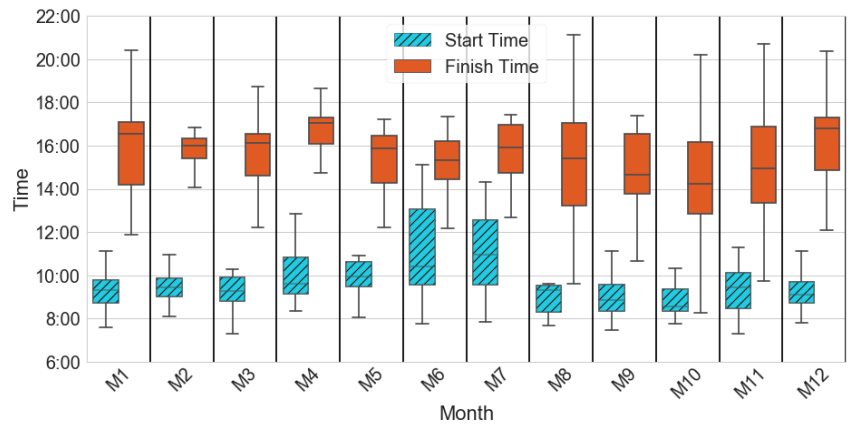

Figure 2: DementiaWall use: monthly averages of the daily start, and end times

of content, and the process of domesticating the wall-sized display. The themes were discussed among researchers to reach consensus.

\section{FINDINGS}

\section{Overall Experience and Engagement with DementiaWall}

Log data indicates that the DementiaWall was used most days (79\%), and predominantly on weekdays (93.5\% of all weekdays, and $39.4 \%$ of all weekends). Early months average around 8 hours of daily use ( $9 \mathrm{am}$ to $5 \mathrm{pm}$ ), which drops to around 5-6 hours after the fourth month (with the lowest use occurring over winter months and then increases back to 8 hours towards the end of the year (when there is also more frequent use after 8pm) [Figure 2]. This extended late use was due to the identified benefit for residents' behaviour needs in the evening: "we now leave [it] on, in the evenings as well, because the advantages [for the residents], who may be bit [tired and agitated]" [S2].

The active engagement with DementiaWall throughout the informal interventions it enabled, has also been reflected in increased use of the room and its occupancy by both residents and visiting families, as it become integrated in residents' and visitors' routines: “families are saying 'let's go into the room with the big screen' when they come to visit, they like to go in there [and] enjoy the scenes" [S7]. As we detail later, this engagement relates to the four informal interventions inspired by the display and their perceived specific benefits for residents' wellbeing through increased sensory, cognitive, and social stimulation, and in particular mood and behavior regulation: "I think we all agree, that screen is just lovely for the ladies" [F3], "it is amazing" [F2], "very good [...] it settles them down [residents experiencing agitation]" [R1]. In turn, this led to a significant outcome regarding strong attachment to the DementiaWall, expressed by most participants. In particular, without prompting, three participants expressed concerns for having it removed at the end of the project, and interest to explore alternative, affordable substitutes: "it will be a shame to lose the screen [...] and I presume it's the screens that are expensive [...] we see it being appreciated and we appreciate it, but equally, given the cost factor, [we are thinking] whether or not it can be made smaller" [F7]. These outcomes are 


\begin{tabular}{|c|c|c|c|}
\hline Digital plumbing & \multicolumn{3}{|c|}{ Co-designing informal interventions } \\
\hline $\begin{array}{c}\text { Setting up } \\
\text { Maintaining }\end{array}$ & $\begin{array}{c}\text { Sourcing } \\
\text { content }\end{array}$ & $\begin{array}{c}\text { Exploring content types } \\
\text { for dementia needs }\end{array}$ & $\begin{array}{c}\text { Monitoring } \\
\text { impact }\end{array}$ \\
\hline researchers & $\begin{array}{l}\text { care staff } \\
\text { residents } \\
\text { families }\end{array}$ & $\begin{array}{l}\text { care staff } \\
\text { researchers } \\
\text { families }\end{array}$ & $\begin{array}{l}\text { care staff } \\
\text { researchers } \\
\text { families }\end{array}$ \\
\hline
\end{tabular}

Figure 3: Two stages of digital plumbing and co-designing interventions (1st row), their activities (2nd row), and social actors (3rd row) involved in the DementiaWall's domestication (Icons: CFreepik @Good Ware)

important given consistent findings that show users' disengagement from large displays after a period of the novelty effect wears off, and with most deployments seldom securing use beyond six months [50].

\section{DOMESTICATION OF DEMENTIAWALL}

We now look at how DementiaWall impacted on the residential care home, both in terms of the house itself, and the care practices. Originated in media research, domestication describes how media technologies become part of people's lives from the stage of acquisition and placement into the home, to their integration in household's routines; a process entailing double adaptation: of technology to the home, and of the home to technology [102]. While much work has focused on families and their homes as sites for domestication [9], its exploration in the context of old age and dementia has been limited, although recent work suggests care staff's challenges of using and maintaining assistive technologies deployed in older people's homes due to lack of skills and time [85]. Our findings indicate five domestication activities: setting up and maintaining the DementiaWall, plus three interrelated activities pertaining to the co-design of informal interventions, namely sourcing media content, exploring the coupling between content and the stimulation needs of those with dementia, and monitoring interventions' impact [Figure 3]. Each activity involved different configurations of social actors with the care staff driving the co-design stage.

Digital Plumbing: Setting up \& Maintaining DementiaWall The setup and maintenance work required from owners before using novel technologies in their homes has been described as digital plumbing [111] but has received limited consideration in sensitive settings. However, the deployment of technologies, and in particular ubiquitous ones, requires much care in sensitive settings [83]. Thus, together with the owners, we made careful choices regarding the placement, size, and shape of the display while sensitively informing both residents and families of the planned deployment. Regarding placement, the choice of the lounge was made after much consideration: this room was previously used for group reminiscing - a screen projector created a temporary display but the resulting image quality was unsatisfactory. Despite such occasional use, this room lacked a clearly defined function: "it didn't have specific purpose [and now] there is something for people to go in there for [...] We have the advantage of having different spaces [...] so, people have choice really, in what mood they are in, or what they want to do" [S1]. While one end of the room was bright due to the presence of two large windows, the size and shape meant that the entrance was dark and thus a large display could act as a focal point while avoiding glare. As a result: "[the room is] utilized a lot more now, definitely [...] some of them go in there and then be there for ages" [S6]. The shape and size of DementiaWall evolved (prior to placement) through conversations with the owners, from a flat, two screen high display, towards a partially immersive, three screen high display in a ' $L$ ' shape expected to support more stimulating and immersive experiences: "wrapping around a little bit, that's very nice [...] I don't think any bigger in that room, would be particularly good, and I don't think it would be good to be in a different space either" [S5].

We know that technologies are more likely to be domesticated if they fit rather than disrupt the house's infrastructure [110] identified as consisting of three layers: Stuff or moveable objects; Space or walls, windows, doors' layout; and Service of utilities and communication technologies. Setting up involved significant alterations at Space layer to ensure screens' secure mounting and their precise alignment to create a video wall. While the mounting was concealed behind the display, the changes at the Space layer were not, given the new look of the room hosting the DementiaWall. The set-up did not involve alterations at Service layer, although towards the end of the year the need for upgrading internet service to fiber optic for better streaming of content has been identified, while the changes at Stuff layer were minimal, involving the orientation of chairs and armchairs in the room towards the display. An interesting outcome is owners' envisaged ways of further extending the DementiaWall through additional alterations to the Space layer by increasing its height up to the ceiling, and integrating surrounding sound or ambient light: "[so that when] people are getting anxious [...] we have soothing colours, and natural scents [...] more conducing [to sensorial experiences]" [S7].

With regard to maintenance, as researchers, we provided remote support comprising of a combination of remote desktop access (Teamviewer) and over-the-phone/email troubleshooting. However, the use of robust ubiquitous technology and simple interface for interacting with the DementiaWall has ensured ease of use, with only minor maintenance issues regarding getting all 9 of the displays to turn on at the same time, due to inappropriate shutting down.

\section{Co-designing Informal Interventions}

A key finding is the underlying theme of personhood informing the overall approach to dementia care in three important ways, through both traditional interventions and novel ones inspired by the DementiaWall. First, is the care staff's rich knowledge of residents' lives and interests also supported by an in-house technology like Portrait [120]: "we know [our] ladies [and we] can tell if somebody is not happy [allowing us] going in their world, whatever their world happens to be today [because] it might be different tomorrow" [S2]. Second, is the abundance of activities supporting such interests from 

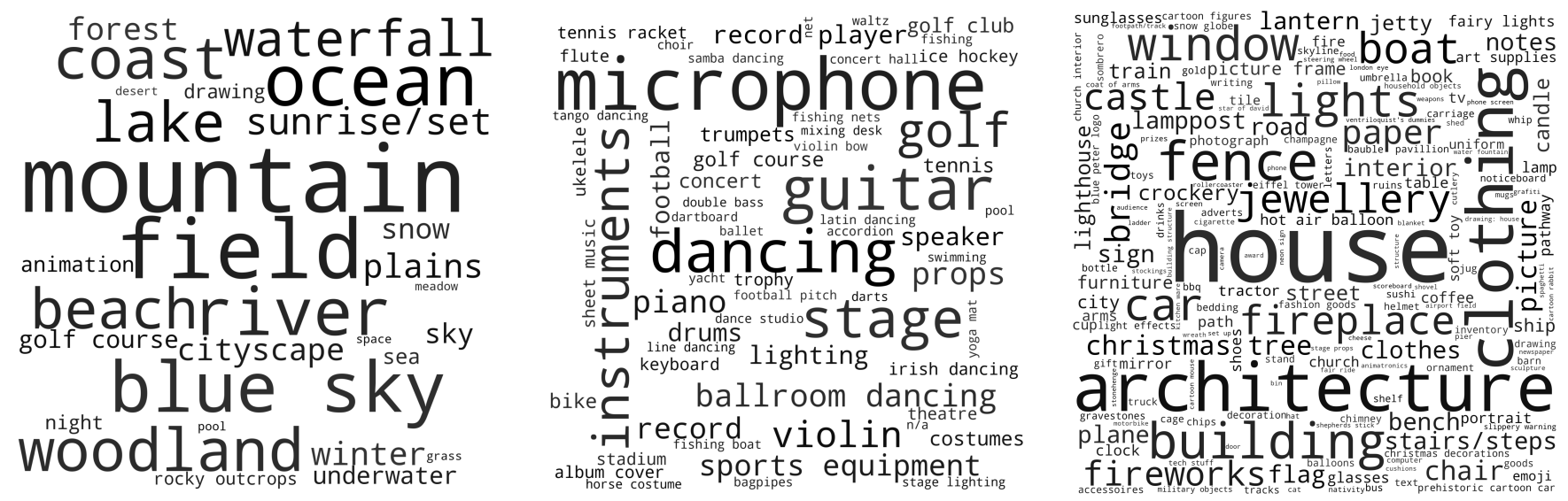

Figure 4: Word clouds of displayed YouTube content across the three main categories: nature (left), entertainment (middle), and lived life (right), relevant to three of the informal psychosocial interventions inspired by the DementiaWall: nature-inspired, "seen" music, and reminiscing, respectively.

one-to-one reminiscing to cooking, baking, flower potting, listening to music, interacting with visiting children, singing or dancing: "they do a lot of other activities as well as that [the DementiaWall]" [F5]. Third, is the pervasive practice of providing choice: of activities, meals, entertainment, clothing, room decoration. In turn, we have many accounts of residents' improved physical and emotional wellbeing like in this illustrative quote:

"it was very hard to get her to eat [...] I bought her in on Friday, and phoned Saturday afternoon [spoke to the chef who] said 'who, Jessica? isn't she lovely? I've met her this morning when I went in, to see what she wanted for breakfast [...] she asked for porridge and a cup of tea [...] and am saying: 'She asked for [this]? She spoke?! [...] and she's carried on [...] went from size 6 [to] size 12” [F1].

The provision of informed choice has been consistently mentioned with regard to the DementiaWall, from the choice to be in the room: "I would, by default, put a relaxing [video], because that's quite nice just for people to come in. Sometimes, [they do but] not always" [S2], the choice to experience immersion: "what's great about that screen is that if they just turned away from [it], they are not immersed in it. It's optional" [S1], to the choice of films or videos: "we just asked people what they would like " [S7]. In addition, all the displayed content was tailored to residents' immediate needs which could further strengthen personhood. The domestication of the DementiaWall through the design of novel interventions has led to new routines for the care staff such as sourcing online content, exploring its value for residents' stimulation needs, and monitoring their impact.

\section{Sourcing Online Media Content for the DementiaWall}

The displayed media content was predominently videos, most from online sources. Indeed, from the 2344 captured interactions with the DementiaWall, 2199 related to the use of Chrome - confirming thus that most of the content was streamed from websites, predominantly YouTube (79\%) and BBC iPlayer (2\%). As captured data indicates, typically an average of six items of media content were displayed daily. Local videos played using Windows Media Player or similar applications accounted for $3 \%$ of content as did the Windows DVD player. Photos viewed using the Windows photo viewer represented less than $1 \%$. Interview data revealed the following categories of video content (whose typical duration ranged between one to three hours) in decreasing order of use: nature based content (seaside, forests, countryside, flowers, foliage, birds), entertainment (films, music, dance, sports), past lived life (tools and activities, documentaries), inhabited places (cities and buildings), and photos. These categories highlight two important insights. First, the predominance of nature based content has been seldom used in HCI research for dementia, despite findings on the restorative value of nature [16]. Second, the limited use of photos is surprising, given the extensive use of media biographies in dementia care [20, $120]$, and the increased value of personalized content [2, 3, 87]. Apart from online, the content shown on the DementiaWall was occasionally sourced from DVDs, and less from residents' photos.

These video categories were also revealed by the log data indicating that the most often shown media content (top 20 items) included nature (relaxing countryside, nature sounds of forest, stunning nature, and beaches), ballroom dancing and music (classical, relaxing instrumental), sport (golf). In addition, we also conducted a content analysis of over half of the 1,333 unique YouTube videos that were played through the study. For each video, the default YouTube screenshot was automatically generated and three coders worked together to tag a randomly selected subset of just over half the images $(\mathrm{n}=757)$ across categories such as landscapes, natural objects, man-made objects, sport, genre and decade (of music, film or TV). Figure 4 shows the word clouds for the three main categories of content identified based on interview data, and relevant for three of the four informal psychosocial interventions inspired by the DementiaWall. The fourth intervention of mediated staged experiences has been supported mostly by 
offline photos therefore its content is not reflected within the word clouds.

\section{Exploring Content Types for Distinct Stimulation Needs}

Outcomes indicate that the care staff successfully engaged in creative exploration of the DementiaWall, in order to design novel interventions: "we try to see the benefits [of new interventions] and [use staff's] imagination [to] do activities [...] have got a few carriers that come up with ideas [...] prompted [by] the screen [...] I think that we have become more creative realizing more things that you could do like [...] getting them iPad or sport scenes" [S7]. This quote from one of the care home owners highlights two important things. First, the DementiaWall is open to all for exploration, that is actively encouraged by the owners, and second, its long-term use has allowed for more innovative interventions to be designed, and as observed to also extend to more innovation in the offline interventions. Another significant outcome is that this democratic engagement with the DementiaWall has also been extended to include family members who have deliberately started to take on the role of curators of personally relevant media content. Such content consists of photos of significance for their loved ones to be displayed on the DementiaWall by care staff, either in family restricted settings, or with other residents: "Mom has never been to Rome but she knows all the artists [...] So I'm actually going to bring some pictures and put them on the screen and talk to the other ladies as well about how it is to be in Rome" [F8]. This intention to show personalized content on DementiaWall is important, aligning with the emerging trend towards personalizable displays [25] yet contrasting with existing privacy mechanisms aimed to ensure tight control over residents' photos on tablet-based technology [120]: "we have agreements with residents and their families [regarding confidentiality]" [S9].

\section{Monitoring Interventions' Impact}

The participatory research approach to the co-design of informal interventions has become particularly relevant in the care staff's monitoring of the value of the display and its content for supporting residents' wellbeing: "it is experimental really [...] figuring out what works, what doesn't. We can change it day to day, if we see something works marvelously one time, and then the next time it doesn't work at all, because people change [...] different moods on different days" [S5]. The importance to attend to the residents' needs in the moment requires an agile, explorative approach of different types of content for specific needs from alleviating agitation to supporting social connection: "so she walks around [and] we found something on the screens that she likes: ballroom dancing. But, lately she's gone off from that, so we'll have to find something else that triggers that. We don't have a specific thing" [S3]. In other words, the care staff has developed a range of interventions which they continue to refine and personalize through specific media content as described in the following section.

\section{Psychosocial Interventions Facilitated by DementiaWall}

DementiaWall has inspired four types of informal psychosocial intervention leveraging specific media content to support sensory, emotional, social, and cognitive stimulation. While interventions supporting cognitive stimulation for reminiscing and sensory stimulation through music [104, 123] are somehow less surprising, we argue for the novelty of the others and start with their descriptions, highlighting also all interventions impact on residents' and visiting families' routines.

\section{Nature-inspired Media: Mood and Behavior Regulation}

An important outcome is the value of nature-based content shown on the DementiaWall for mood regulation, particularly videos of seascapes and forest landscapes. Almost all participants mentioned the importance of videos showing sunny white beaches, and waves breaking gently on the shore, to help residents in agitated states to calm down and relax (Figure 1).

"It is really beneficial and very attractive [as] with severe dementia, there is a lot of walking, so that [one resident] almost exhausts herself, [but with] the right image she would relax [almost instantaneously]: shoulders would drop and she would sit and look at the screen [...] flowers and beach, sea, moving water [...] moving foliage, natural things. Yes, really very calming. [...] and it might only be for 5, 10 minutes before she remembered she was walking. But it was 10 minutes of relaxation, she wouldn't have otherwise" [S5]. This illustrative quote also highlights the important aspect of nature-based movement and its qualities: "you've got a brook with running water [...] and that's the only movement in the scene; quite therapeutic" [S1]. Natural, rhythmic movements and sound (e.g. ocean or sea waves) were strongly valued. Such content-related findings provide a more nuanced understanding of the restorative value of nature in dementia [16]. We now compare these nature-based interventions on the DementiaWall with the traditional nature-based ones taking place in the care home such as flower potting, or time spent in the garden. Although enjoyable, the latter are less frequent, being season- or weather-dependent. In contrast, the DementiaWall is used most days, and particularly important, for the specific benefits of reducing agitation. Arguably, even more important is that it provides increased immersion and enjoyment from perceiving "real size" [60] videos of, not directly accessible, relaxing nature: "I think they are very good and very relaxing especially some of the beach scenes, the woodland scenes [...] when I came in yesterday, mom was in there watching" [F3], and also by one of the residents: "you need to see Australia [beach videos] it's always hot and sunny, and that makes us all...relaxed. I think it's definitely therapeutic [...] the sound of moving water as well" [R1].

Mediated Staged Experiences: Sensory \& Social Stimulation An important finding is the innovative use of the DementiaWall for imbuing performative qualities to daily life experiences such as those of being in the cinema, restaurant, or church: "We have cinema afternoons: [we show old movies and] dress up as majorettes and have the hats, popcorns, and ice cream to sell [it is] atmospheric. [We] put curtain up, and they have to enter through [and exchange tickets] as if you went in a proper cinema [...] interesting thing is that some people who would want to go to toilet every 2 or 3 minutes, they are not for long period [but] really engaged [in the] atmosphere" [S7]. Besides immersion "because [the DementiaWall] is wrapped around [it feels like] you are there, you are part of it" [S1], similar quotes reported changes in residents' behaviour 
through engagement in intentionally designed multisensory experiences that bring people back in time: "she was concentrated [...] it was an interesting flick to that atmosphere [so] we are seeing additional benefits" [F7]. The shown movies, some suggested by residents, facilitate enjoyment and often remembering: “one of the ladies [suggested King's Speech movie] which is a good one because it's got a lot of their time, you know the war, and they would remember all this" [S1]. However, instead of relying on conversation for reminiscing, these experience based interventions prioritize sensory and social stimulation, offering opportunities for novel social exchanges, or what F7 called moments of "comfortable silence, while we are all normally watching the screen", further detailed by F8: "is a bit liberating when you can actually sit and [...] we don't have to be talking; just watch in a relaxed atmosphere [...] now, she's more relaxing, she enjoys the visits better". This suggests that social stimulation afforded by these interventions is beneficial for both residents and their families, as reflected in their increased participation: "there must have been 15 people in there [...] surprisingly a high number" [S9].

Other staged experiences are those of Sunday mass: "we have used the screen [...] for Communion service sometimes [with] the image [on the DementiaWall from] inside of church [...] so for them it would be a reminder of what is like to be inside the church" [S5]. This familiarity with the local church and its real size image supports a sense of presence: "she knows [the church and] she was sort of sitting there, looking at it like there was a very familiar environment [...] she must have felt as if she was in the church" [F8]. While cinema and church experiences also support remembering, the staged experience of restaurant dining provides novelty: "we set the tables, just like in a restaurant, and when we had the Chinese one [...] we had the chant music with the pagodas in the background [as photos]" [S3], and enjoyable immersion: "when we came for the Chinese meal with mom, you felt you were in a Chinese [restaurant] with all the lanterns [...] it felt, really, quite vivid, the feeling of being there" [F9]. By supporting a sense of presence: "[one evening we had] Bollywood scenes [and] suddenly she was part of the dancing and the music, she was kind of engaged within" [S7]. Staged experiences were particularly appreciated as the residents' physical declining increasingly limited their access to such places: "she's a bit frustrated about her mobility [and is also] incontinent [so] she worries [...] we can't really take her to a restaurant or a café" [F6].

\section{"Seen" Music: Sensory Stimulation \& Mood Regulation}

Findings indicate that different types of music support different levels of sensory stimulation, which in increasing order are: classical music, vocal upbeat music, ballroom music and dancing, and karaoke singing. The highest levels of stimulation relate to residents not just listening but also watching ballroom dancers, or engaging in singing: "By default I would put the relaxing [videos] on [nature sounds or classical music], but if I feel that somebody is getting a bit restless, I might put on ballroom dancing [for not more than an hour] as they can't concentrate longer. [And] I tend to put karaoke [...] mostly if [one resident] is getting agitated [because] generally that helps, and others might come in and join us [...] she used to teach music [...] so she responds to that [...] today we also had golf on for quite a long time because one lady loves looking at it" [S2]. This quote indicates intentional selection of music to meet residents' needs for mood regulation, which extends a similar intervention with relaxing or upbeat music being delivered on a media player in the main room: "sometimes, they want to sleep so I put some classical music on, and sometimes they are very chatty and I put a bit of upbeat Bill Haley on but not too loud because that will get on their nerves" [S3]. While these activities are engaging and stimulating on radio, when delivered on the DementiaWall they enable also a performative stance, where the 'music can be seen' through people playing, singing, or dancing. As a result, residents "watching" instead of merely "listening" music have a richer - more immersive and embodied experience: "she liked watching [...] dancing and when I was in there watching, she reached out to the screen" [F2]. Such activities are also enjoyed because they are shared enabling residents to further see and enact bodily movement through music: "yesterday, mom was in there watching others sing along and she was doing 'Roll up the barrel' [popular polka song from the WWII] happily singing along” [F3].

\section{Collectively Relevant \& Personal Media: Reminiscing}

Two key findings regarding reminiscing interventions on the DementiaWall are the limited use of personal photos, and the extensive use of online generic content which we call collectively relevant: "things that they are going to remember and relate to: [past life themes from] 1930s [to] 60s [...] clothes, transport, education, holidays, kitchen of the [time] [as many] of them [were] housewives [...] Quite a few of them might say, 'I really enjoyed that, thank you' or they become more animated [...] Two of them don't have children [so we] have to do more one-to-one [reminiscing]" [S2]. Such content, used in group reminiscing activities, consists of prototypical generational experiences from residents' reminiscing bump periods; the last to be lost in dementia [43]. Such life size, often black and white content and its soundtrack from the media at the time, allows links to personal memories, and almost a sense of presence back in time. While largely effective, such generational experiences tend to be however embedded within the broader UK social culture, becoming less relevant to a few residents of different ethnicities: "[these activities] were relevant to the other residents, but obviously for mom [born and raised in East Africa], they are not" [F9].

We also mentioned the limited use of residents' photos on the DementiaWall and associated confidentiality concerns. An important outcome is that towards the end of the year we have started to see such uses emerging while accounting for privacy. Indeed, in a few instances when personal photos were displayed, they were used to support individual rather than group reminiscing, with facilitation from family members. One such activity was requested by F9: "[because] my mother would have different kinds of memory [of the sea without] sandcastles and buckets and all. It would be just the tropical beach", so "the family brought in [sea] pictures on a CD, and we put them on the screen [as slide show and they all watched and helped her] remember and were very, very supportive" [S9]. These activities suggest that the extended use of DementiaWall was 
associated with the incorporation of personal material sourced by families, rather than only by the care staff. Prior technologies allowed one-to-one reminiscing using residents' photo albums and tablet-based technology [120]. Compared to these, the DementiaWall allowed access to larger, real size images supporting a sense of presence and addressing visual impairment: "I've been [...] looking at photographs in her album with her. And they are tiny, because it was 1930s, so there is very small detail, so you can guess what enlarged would be [...] she'd be fascinated" [S5].

\section{DISCUSSION}

The significant engagement and adoption of the DementiaWall through the identified psychosocial interventions, has led to increased use over its year-long deployment, and participants' strong attachment, as the display became weaved in the fabric of the residential care home. This is an important outcome, as consistent findings on public displays have shown limited engagement and adoption $[12,14,46]$, or that their immediate novelty does not last beyond 6 months [50]. Part of the DementiaWall's successful domestication and long-term adoption can be linked to a breadth of key factors previously suggested $[46,50]$ to supporting engagement such as its high value for residents, families and care staff and therefore their motivation to engage; low skill requirement and easy interaction, home owners' acting as strong champions, and its flexible support for multiple functions provided by the different interventions. We also add to these the importance of participatory research approach to deployment, which contrasts previous findings indicating its impact on reducing the novelty effect [50].

In particular, the DementiaWall inspired novel interventions, two of which leverage music and reminiscing therapeutic approaches. We have seen however key differences between these interventions delivered on the DementiaWall and their closest traditional counterparts. First, the DementiaWall facilitated richer experiences: multisensory, immersive, and embodied across all four interventions from the movement and sound of real size nature scenes, or music players and dancers, to the real size images from the past and their sound track, and of course to the staged experiences with rich digital and physical props. Second, through its ease of use, the DementiaWall allowed scaling up the delivery of these interventions over the entire year while many structured interventions last at most four months. Finally, the DementiaWall flexibly supported all four types of interventions through the increasingly familiar wall-sized display and different media content, easily sourced online by the care staff to address in-the-moment residents' individual and collective stimulation needs. By becoming integrated in residents' routines, the attachment to the DementiaWall attracted more people to its room, offering opportunities for more interventions which, importantly, have not replaced traditional ones taking place in the home, but innovatively extended them. While three interventions facilitated increased stimulation: sensory, social, and cognitive, the nature-based one supported what we would call a more balanced stimulation leveraging the restorative value of nature [16] media, similar to sensory garden [37] and the principle of reduced stimulation [15], predominantly reflected in our findings through slow and rhythmic movement of water. In the staged experience intervention which facilitated sensory and social stimulation, the focus was on the social interactions augmented by the display for traveling with loved ones to old times and places.

While large displays have been shown to connect physical spaces for enjoyment [5, 10, 36, 38], the DementiaWall also facilitated togetherness, an important benefit in care homes [40]. The sensory stimulation in music intervention confirmed the value of instrumental, slow tempo, low volume music for relaxation [67], and of upbeat rhythmic music for engagement [63], but also the value of seeing real life human bodies playing music, singing or dancing, which allowed for richer embodied experience. These insights on the value of different media items for specific stimulation needs can open up new design opportunities for dementia technologies. We can think of ambient displays responding to noise level to provide adaptive imagescapes and soundscapes leveraging the benefits of natural movement [33] for wellbeing and relaxation, or opportunities to design for comfortable silences through which families and their loved ones can share embodied experiences of togetherness, emphasizing "being" rather than "doing". We can also imagine novel multimodal interfaces allowing for music to be "seen" through embodied, shared experiences of movement and rhythm.

\section{Strengthening Personhood through Exercising Choice}

Outcomes indicate several ways in which the DementiaWall supported personhood, from celebrating togetherness to providing residents with ample and consistent opportunities to make decisions regarding their interaction with the display, both explicitly through choosing to: be in the room, watch the displayed content or request specific content; to more tacit forms of interaction through which their interests and moods informed the care staff's choice of tailored content. These outcomes are significant, given that findings have shown that being informed of available choices, and having one's personal interests accounted for, may be more important for personhood in dementia than the decision making itself [64]. Our outcomes complement the HCI emphasis on the agency of interacting with materials and creating something new through crafts $[19,118]$, with the provision of opportunities to exercise choice in care setting [32,103]. Without being mutually exclusive, these two approaches echo Archer's [4] distinction between supporting what people do, and what they say.

\section{Generic vs Personal Content; Public vs Private Use}

The use of the DementiaWall for group reminiscing highlighted more extensive use of generic content than previously explored, i.e., recreation, entertainment and local life themes [2], albeit with stronger injection of personal relevance, going beyond individual's personal interests [3]. Study outcomes indicate different strategies for injecting personal relevance into online generic content by leveraging similarities among residents' lives both temporal, in terms of shared generational experiences particularly from residents' reminiscing bump periods [43] such as WWII; and spatial, in terms of shared local knowledge of the town and its surroundings. Generic content was also sourced to reflect residents' commonly shared identities and interests, as most of them were housewives with 
interests in domestic activities. These outcomes are important as they challenge the advocated dichotomy between generic and personalized content $[2,3]$. In contrast with the extensive use of such generic content on the DementiaWall, personal content was limited due to either confidentiality issues, or the nature of the content consumption in a public room. We have seen however emerging novel uses of private photos consumed, in restricted public context, solely by the resident and her family. This opens up an interesting design space for novel forms of consumption of personal material on public displays for both personal and collective reminiscing, extending the current restricted use of personal content to small screens [20, 122], with the need for more nuanced understanding of sharing practices for vulnerable users [17].

\section{The Value of Participatory Research in Domestication}

We now turn our attention to the domestication of the DementiaWall and its qualities as infrastructure prototype, while highlighting also the importance of participatory design and research approach. Before doing that, we note that there are diverse and competing approaches to how participatory design is defined and used in HCI [73, 30, 39, 115]. DementiaWall was successfully domesticated despite the significant alterations at Space layer, which previous work suggested that should be kept minimal for the domestication of internet technologies [29], screens and cameras [110], energy monitors [94], or digital media [83]. Thus, what appears to matter for our wall-sized display is not merely minimal alterations, but active engagement from the care staff in sourcing its content. Our participatory research approach to the domestication of the DementiaWall allowed for the emergence of research-informed, naturalistic interventions, outside researchers' authoritative influence and academic privilege [70]. In this way, we transitioned from collaborative to collegiate researchers, working with the care staff towards mutual learning and sharing of research authority [18] while they led the co-design of the interventions. The value of ubiquitous infrastructures for enabling novel activities with user-driven media content has been referred to as opportunity space [45], and we argue that the exploration of this space can be more impactful through participatory research approach. Ownership, as key aspect of participatory research, also surfaced in our project as the wallsized display become part of the fabric of the care home. Given its high quality screens and complex mounting, the DementiaWall's cost is beyond the reach of most small-to-medium size care facilities, raising thus challenges for sustainable use. We made a commitment to extend the use of the DementiaWall until we provide alternative cost effective solutions such as projectors which would have to address owners' initial concerns of quality, heat, noise and aesthetics. We have already started to develop lab-based prototypes using lighting projector with low visual noise designed to mimic the appearance of spotlights for which any wall with surface treatment may act as screen. These efforts are aimed to ensure sustained capacity for our collaboration as a key aspect of participatory research.

\section{Infrastructure-based Prototypes}

We define infrastructure-based prototype as consisting of complex large-scale infrastructure deployed for continuous longterm use, in real settings, to support a generic functionality whose content can be creatively explored to support different social practices. A useful metaphor for infrastructure-based prototypes is that of "blank canvas" on which users, as curators of content, can draw on.

Reflecting on the generative quality of the DementiaWall as such a prototype, we start by acknowledging the distinction between generative and evaluative design approaches and their rather distinct methods for divergent ideation and converging synthesis, $[11,44]$ that has traditionally considered prototypes as technically implemented tools for evaluation, employed later in the design process. In contrast, generative tools emphasise playful exploration $[11,47,116]$ with limited technical implementation of their main function, and employed earlier in the design cycle to identify future design options. However, as our findings show, the long-term deployment of the DementiaWall prototype allowed not just its positive evaluation leading to strong attachment, but also its generative quality, as it become creatively appropriated for different psychosocial interventions. This generative quality relates to novel current uses served by the same main function, i.e., sourcing of online content, rather than different future functions like in the case of the generativity supported by technology probes [11, 47].

Thus, our outcomes indicate the DementiaWall's potential to be used for both evaluation and generative purposes, the importance of which has been indicated $[42,86]$ at theoretical level through strong concepts [44] and other types of design knowledge [97], but explored less at artifact level. In our case, the generic functionality was: online content sourcing, and social practices: psychosocial interventions, but we can think at other scenarios decoupling function from content generation such as the one of music composition, illustrated for instance by A20 technology probe using "musical instrument" metaphor of open ended system [8], similar to our "blank canvas" metaphor. Our method and infrastructure-based prototype may also be relevant to other research areas such as urban screen design [74], or pervasive displays [24, 22, 25, 23, 106] which future work could further explore.

\section{CONCLUSIONS}

Our exploration of the DementiaWall's domestication over its year-long deployment suggests the value of large displays for personhood in dementia which has been supported by four specific interventions addressing distinct stimulation needs. We advance the theory for collective reminiscing technologies through a more nuanced discussion of the tension between generic/personal content and its public/private use, and on domestication by highlighting the importance of participatory research, and of the generative quality of the DementiaWall as a novel infrastructure-based prototype.

\section{ACKNOWLEDGMENTS}

This research was partially supported by the UK EPSRC funded PACTMAN project (EP/N028228/1) and EC H2020 funded AffecTech: Personal Technologies for Affective Health, Innovative Training Network (722022). We also thank Mr Paul Rowley at Heathfield home, and Prof Vicki Hanson for constructive feedback on the manuscript, and all participants for willingness to support this work. 


\section{REFERENCES}

[1] Hedda Agüero-Torres, Laura Fratiglioni, Zhenchao Guo, Matti Viitanen, Eva von Strauss, and Bengt Winblad. 1998. Dementia is the major cause of functional dependence in the elderly: 3-year follow-up data from a population-based study. American Journal of Public Health 88, 10 (1998), 1452-1456.

[2] Norman Alm, Richard Dye, Gary Gowans, Jim Campbell, Arlene Astell, and Maggie Ellis. 2007. A communication support system for older people with dementia. Computer 40, 5 (2007), 35-41.

[3] Sérgio Alves, Filipa Brito, Andreia Cordeiro, Luís Carriço, and Tiago Guerreiro. 2019. Designing Personalized Therapy Tools for People with Dementia. In Proceedings of Conference Web For All. ACM, New York, NY, USA, 33.

[4] Margaret Archer. 2000. Being Human. The Problem of Agency. Cambridge University Press, Cambridge, UK.

[5] Artichoke. 2008-2012. The Telectroscope by Paul St George. 22 May - 15 June 2008. London | New York. http://www.talktalk.co.uk/telectroscope/home.php [Last accessed: October 2012]. (2008-2012).

[6] Rosemary Bakker. 2003. Sensory loss, dementia, and environments. Generations 27, 1 (2003), 46-51.

[7] Robert Ball and Chris North. 2007. Realizing embodied interaction for visual analytics through large displays. Computers \& Graphics 31, 3 (2007), 380-400.

[8] Olivier Bau, Tanaka Atau, and Mackay Wendy E. 2008. The A20: Musical Metaphors for Interface Design. In Proceedings New Interfaces for Musical Expression (NIME 2008). 91-96.

[9] Thomas Berker. 2005. Domestication of media and technology. McGraw-Hill Education, UK.

[10] Sara A. Bly, Steve R. Harrison, and Susan Irwin. 1993. Media Spaces: Bringing People Together in a Video, Audio, and Computing Environment. Commun. ACM 36, 1 (January 1993), 28-46.

[11] Kirsten Boehner, Janet Vertesi, Phoebe Sengers, and Paul Dourish. 2007. How HCI Interprets the Probes. In Proceedings of the SIGCHI Conference on Human Factors in Computing Systems (CHI '07). ACM, New York, NY, USA, 1077-1086.

[12] Harry Brignull and Yvonne Rogers. 2003. Enticing People to Interact with Large Public Displays in Public Spaces. In Proceedings of INTERACT, Vol. 3. 17-24.

[13] Di Chen. 2011. The effects of screen size, production pacing and use experience on attention and arousal. $\mathrm{Ph} . \mathrm{D}$. Dissertation. Indiana University.

[14] Elizabeth F. Churchill, Les Nelson, Laurent Denoue, Jonathan Helfman, and Paul Murphy. 2004. Sharing Multimedia Content with Interactive Public Displays: A Case Study. In Proceedings of the 5th Conference on
Designing Interactive Systems: Processes, Practices, Methods, and Techniques (DIS '04). ACM, New York, NY, USA, 7-16. DOI :

http://dx.doi.org/10.1145/1013115.1013119

[15] T Anne Cleary, Cheryll Clamon, Marjorie Price, and Gail Shullaw. 1988. A reduced stimulation unit: Effects on patients with Alzheimer's disease and related disorders. The Gerontologist 28, 4 (1988), 511-514.

[16] Jiska Cohen-Mansfield. 2004. Nonpharmacologic interventions for inappropriate behaviors in dementia: a review, summary, and critique. Focus 9, 2 (2004), 361-308.

[17] Raymundo Cornejo, Robin Brewer, Caroline Edasis, and Anne Marie Piper. 2016. Vulnerability, Sharing, and Privacy: Analyzing Art Therapy for Older Adults with Dementia. In Proceedings of the 19th ACM Conference on Computer-Supported Cooperative Work \& Social Computing (CSCW'16). ACM, New York, NY, USA, 1572-1583.

[18] Andrea Cornwall and Jewkes Rachel. 1995. What is participatory research? Social science and medicine 41 (1995), 1667-1676. Issue 12.

[19] Andy Crabtree, Terry Hemmings, Tom Rodden, Keith Cheverst, Karen Clarke, Guy Dewsbury, John Hughes, and Mark Rouncefield. 2003. Designing with care: Adapting cultural probes to inform design in sensitive settings. In Proceedings of Australasian Conference on Computer-Human Interaction (OZCHI'04). ACM, New York, NY, USA, 4-13.

[20] Masashi Crete-Nishihata, Ronald M Baecker, Michael Massimi, Deborah Ptak, Rachelle Campigotto, Liam D Kaufman, Adam M Brickman, Gary R Turner, Joshua R Steinerman, and Sandra E Black. 2012. Reconstructing the past: personal memory technologies are not just personal and not just for memory.

Human-Computer Interaction 27, 1-2 (2012), 92-123.

[21] Mary Czerwinski, George Robertson, Brian Meyers, Greg Smith, Daniel Robbins, and Desney Tan. 2006. Large display research overview. In Proceedings of Conference Extended Abstracts on Human Factors in Computing Systems (CHI EA'06). ACM, New York, NY, USA, 69-74.

[22] Nigel Davies, Sarah Clinch, and Florian Alt. 2014. Pervasive Displays: Understanding the Future of Digital Signage. Morgan \& Claypool Publishers, Williston, VT. USA. 1-128 pages.

[23] Nigel Davies, Adrian Friday, Sarah Clinch, Corina Sas, Marc Langheinrich, Geoff Ward, and Albrecht Schmidt. 2015. Security and privacy implications of pervasive memory augmentation. IEEE Pervasive Computing 14, 1 (2015), 44-53.

[24] Nigel Davies and Hans Gellersen. 2002. Beyond prototypes: challenges in deploying ubiquitous systems. IEEE Pervasive Computing 1, 1 (Jan 2002), 26-35. 
[25] Nigel Davies, Marc Langheinrich, Sarah Clinch, Ivan Elhart, Adrian Friday, Thomas Kubitza, and Bholanathsingh Surajbali. Personalisation and Privacy in Future Pervasive Display Networks. In Proceedings of the SIGCHI Conference on Human Factors in Computing Systems (CHI '14). ACM, New York, NY, USA, 2357-2366. DOI :

http://dx.doi.org/10.1145/2556288.2557287

[26] Benjamin H Detenber and Byron Reeves. 1996. A bio-informational theory of emotion: Motion and image size effects on viewers. Journal of Communication 46 (1996), 66-84. Issue 3.

[27] Alan Dix and Sas Corina. 2010. Mobile personal devices meet situated public displays Synergies and opportunities. International Journal of Ubiquitous Computing 1 (2010), 11-28. Issue 1.

[28] Alan Dix and Corina Sas. 2008. Public displays and private devices: A design space analysis. In CHI 2008 Workshop: Designing and evaluating mobile phone-based interaction with public displays. 1-6.

[29] Paul Dourish. 2015. Not the internet, but this internet: how othernets illuminate our feudal internet. In Conference on Critical Alternatives. Aarhus University Press, Aarhus, Denmark, 157-168.

[30] Allison Druin. 1999. Cooperative Inquiry: Developing New Technologies for Children with Children. In Proceedings of the SIGCHI Conference on Human Factors in Computing Systems (CHI '99). ACM, New York, NY, USA, 592-599. DOI :

http://dx . doi .org/10.1145/302979. 303166

[31] Jennifer Fereday and Muir-Cochrane Eimear. 2008. Demonstrating rigor using thematic analysis. Journal of qualitative methods 5 (2008), 80-92. Issue 1.

[32] Deirdre Fetherstonhaugh, Tarzia Laura, and Nay Rhonda. 2013. Being central to decision making means I am still here!: the essence of decision making for people with dementia. Journal of aging studies 27 (2013), 143-150. Issue 2.

[33] Paul Fraisse. 1982. Rhythm and tempo. Academic Press, New York, NY, USA. 149-180 pages. Issue 1.

[34] John Fraser, Joe E Heimlich, John Jacobsen, Victor Yocco, Jessica Sickler, Jim Kisiel, Mary Nucci, Lance Ford Jones, and Jeanie Stahl. 2012. Giant screen film and science learning in museums. Museum Management and Curatorship 27, 2 (2012), 179-195.

[35] Susanne Friese. 2019. Qualitative data analysis with ATLAS. ti. SAGE Publications Limited, London, UK.

[36] Kit Galloway and Sherrie Rabinowitz. 1980. Hole-In-Space. http://www. ecafe.com/getty/HIS/ [Index from 7 August 2007 retrieved via the Internet Archive in October 2012]. (1980).

[37] Marianne T Gonzalez and Kirkevold Marit. 2014. Benefits of sensory garden and horticultural activities in dementia care: a modified scoping review. Journal of Clinical Nursing 23 (2014), 2698-2715. Issue 19-20.

[38] George O. Goodman and Mark J. Abel. 1986. Collaboration Research in SCL. In Proceedings of Conference on Computer-supported Cooperative Work (CSCW '86). ACM, New York, NY, USA, 246-251.

[39] Kim Halskov and Nicolai Brodersen Hansen. 2015. The Diversity of Participatory Design Research Practice at PDC 2002-2012. Int. J. Hum.-Comput. Stud. 74, C (Feb. 2015), 81-92. DOI :

http://dx.doi.org/10.1016/j.ijhcs.2014.09.003

[40] G. Hansebo and Kihlgren Mona. 2002. Carers' interactions with patients suffering from severe dementia: a difficult balance to facilitate mutual togetherness. Journal of Clinical Nursing 11 (2002), 225-236. Issue 2.

[41] Richard Harper, Dave Randall, N Smythe, C Evans, L Heledd, and R Moore. 2007. Thanks for the memory. In Proceedings of British HCI Conference, Volume 2. BCS Learning \& Development Ltd., Swindon, UK, 39-42.

[42] Clint Heyer and Margot Brereton. 2010. Design from the Everyday: Continuously Evolving, Embedded Exploratory Prototypes. In Proceedings of the 8th ACM Conference on Designing Interactive Systems (DIS '10). ACM, New York, NY, USA, 282-291.

[43] Alison Holmes and Conway Martin A. 1999. Generation identity and the reminiscence bump: Memory for public and private events. Journal of adult development 6 (1999), 21-34. Issue 1.

[44] Kristina Höök and Jonas Löwgren. 2012. Strong Concepts: Intermediate-level Knowledge in Interaction Design Research. ACM Transactions in Computer-Human Interaction 19, 3, Article 23 (2012), 18 pages.

[45] Eva Hornecker, John Halloran, Geraldine Fitzpatrick, Mark Weal, David Millard, Danius Michaelides, Don Cruickshank, and David De Roure. 2006. UbiComp in Opportunity Spaces: Challenges for Participatory Design. In Proceedings of Conference on Participatory Design (PDC'06). ACM, New York, NY, USA, 47-56.

[46] Elaine M. Huang, Sue Alison, and Russell Daniel M. 2003. On the adoption of groupware for large displays: Factors for design and deployment. In Companion Proceedings of the International Conference on Ubiquitous Computing Seattle.

[47] Hilary Hutchinson, Wendy Mackay, Bo Westerlund, Benjamin B. Bederson, Allison Druin, Catherine Plaisant, Michel Beaudouin-Lafon, Stéphane Conversy, Helen Evans, Heiko Hansen, Nicolas Roussel, and Björn Eiderbäck. 2003. Technology Probes: Inspiring Design for and with Families. In Proceedings of Conference on Human Factors in Computing Systems (CHI'03). ACM, New York, NY, USA, 17-24. 
[48] Phil Joddrell and Arlene J Astell. 2016. Studies involving people with dementia and touchscreen technology: a literature review. JMIR Rehabilitation and Assistive Technologies 3, 2 (2016), e10.

[49] Tom Kitwood and Kathleen Bredin. 1992. Towards a theory of dementia care: personhood and well-being. Ageing \& Society 12 (1992), 269-287. Issue 3.

[50] Michael Koch, Kai von Luck, Jan Schwarzer, and Susanne Draheim. 2018. The Novelty Effect in Large Display Deployments - Experiences and Lessons-Learned for Evaluating Prototypes. In Proceedings of the European Conference on Computer-Supported Cooperative Work: Exploratory Papers (EUSSET'18). 1-19.

[51] Ann Kolanowski, Donna Fick, Christine Frazer, and Janice Penrod. 2010. It's about time: use of nonpharmacological interventions in the nursing home. Journal of Nursing Scholarship 42, 2 (2010), 214-222.

[52] Christian Kray, Keith Cheverst, Dan Fitton, Corina Sas, John Patterson, Mark Rouncefield, and Christoph Stahl. 2006. Sharing Control of Dispersed Situated Displays Between Nand Residential Users. In Proceedings of Conference on Human-computer Interaction with Mobile Devices and Services (MobileHCI '06). ACM, New York, NY, USA, 61-68.

[53] Noriaki Kuwahara, Shinji Abe, Kiyoshi Yasuda, and Kazuhiro Kuwabara. 2006. Networked reminiscence therapy for individuals with dementia by using photo and video sharing. In Proceedings of Conference on Computers and Accessibility. ACM, 125-132.

[54] Amanda Lazar, Caroline Edasis, and Anne Marie Piper. 2017a. A Critical Lens on Dementia and Design in HCI.. In Proceedings of Conference on Human Factors in Computing Systems (CHI'17). 2175-2188.

[55] Amanda Lazar, Caroline Edasis, and Anne Marie Piper. 2017b. Supporting people with dementia in digital social sharing. In Proceedings of the Conference on Human Factors in Computing Systems (CHI'17). ACM, 2149-2162.

[56] Huy Viet Le, Sarah Clinch, Corina Sas, Tilman Dingler, Niels Henze, and Nigel Davies. 2016. Impact of video summary viewing on episodic memory recall: Design guidelines for video summarizations. In Proceedings of Conference on Human Factors in Computing Systems (CHI'O6). ACM, 4793-4805.

[57] Matthew L Lee and Anind K Dey. 2007. Providing good memory cues for people with episodic memory impairment. In Proceedings of Conference on Computers and Accessibility. ACM, 131-138.

[58] Siân Lindley and Jayne Wallace. 2015. Placing in age: Transitioning to a new home in later life. $A C M$ Transactions on Computer-Human Interaction (TOCHI) 22, 4 (2015), 20.

[59] Gill Livingston, Lynsey Kelly, Elanor Lewis-Holmes, Gianluca Baio, Stephen Morris, Nishma Patel,
Rumana Z Omar, Cornelius Katona, and Claudia Cooper. 2014. A systematic review of the clinical effectiveness and cost-effectiveness of sensory, psychological and behavioural interventions for managing agitation in older adults with dementia. Health technology assessment 18, 39 (2014), 1.

[60] Matthew Lombard, Robert D Reich, Maria E Grabe, Cheryl C Bracken, and Theresa B Ditton. 2000. Presence and television. The role of screen size. Human Communication Research 26, 1 (2000), 75-98.

[61] Nancy L Mace. 1987. Principles of activities for persons with dementia. Physical \& Occupational Therapy in Geriatrics 5, 3 (1987), 13-28.

[62] Paul Marshall, Richard Morris, Yvonne Rogers, Stefan Kreitmayer, and Matt Davies. 2011. Rethinking 'Multi-user': An In-the-wild Study of How Groups Approach a Walk-up-and-use Tabletop Interface. In Proceedings of the SIGCHI Conference on Human Factors in Computing Systems (CHI'11). ACM, New York, NY, USA, 3033-3042. DOI : http://dx.doi.org/10.1145/1978942.1979392

[63] R. Mark Mathews, Clair Alicia A., and Kosloski Karl. 2001. Keeping the beat: use of rhythmic music during exercise activities for the elderly with dementia. American Journal of Alzheimer's Disease and Other Dementias 16 (2001), 377-380. Issue 6.

[64] Brendan McCormack. 2017. Negotiating Partnerships with Older People: A Person-Centred Approach. Routlidge.

[65] Nemanja Memarovic, Marc Langheinrich, Florian Alt, Ivan Elhart, Simo Hosio, and Elisa Rubegni. 2012. Using Public Displays to Stimulate Passive Engagement, Active Engagement, and Discovery in Public Spaces. In Proceedings of the 4th Media Architecture Biennale Conference: Participation (MAB '12). ACM, New York, NY, USA, 55-64. DOI : http://dx.doi.org/10.1145/2421076.2421086

[66] Kellie Morrissey and John McCarthy. 2015. Creative and Opportunistic Use of Everyday Music Technologies in a Dementia Care Unit. In Proceedings of Creativity and Cognition. ACM, New York, NY, USA, 295-298.

[67] Ulrica Nilsson. 2008. The anxiety- and pain-reducing effects of music interventions: A systematic review. AORN Journal 87 (2008), 780-807. Issue 4.

[68] World Health Organisation. 2019. Dementia. https://www. who.int/news \protect discretionary $\{\backslash$ char $\backslash$ hyphenchar $\backslash$ font $\}\{\}\{\}$ room/fact $\backslash$ protect \discretionary $\{\backslash$ char $\backslash$ hyphenchar $\backslash$ font $\}\{\}\{$ sheets/detail/dementia. (2019).

[69] Julia O'Rourke, Tobin Fiona, O'Callaghan Susan, Sowman Rebecca, and D. R. Collins. 2011. YouTube: a useful tool for reminiscence therapy in dementia? Age and ageing 40 (2011), 742-744. Issue 6. 
[70] Sonia Ospina, Dodge Jennifer, Godsoe Bethany, Minieri Joan, Reza Salvador, and Schall Ellen. 2004. From consent to mutual inquiry: Balancing democracy and authority in action research. Action research 2 (2004), 47-69. Issue 1.

[71] Daniela Petrelli, Steve Whittaker, and Jens Brockmeier. 2008. AutoTopography: what can physical mementos tell us about digital memories?. In Proceedings of Conference on Human Factors in Computing Systems (CHI'08). ACM, New York, NY, USA, 53-62.

[72] Jean Piaget. 1964. Part I: Cognitive development in children: Piaget development and learning. Journal of research in science teaching 2, 3 (1964), 176-186.

[73] Peter Reason and John Heron. 1986. Research with people: The paradigm of cooperative experiential inquiry. Person-Centered Review 1 (1986), 456-476. Issue 4.

[74] Fiona Redhead and Margot Brereton. 2009. Designing Interaction for Local Communications: An Urban Screen Study. In Human-Computer Interaction INTERACT 2009, Tom Gross, Jan Gulliksen, Paula Kotzé, Lars Oestreicher, Philippe Palanque, Raquel Oliveira Prates, and Marco Winckler (Eds.). Springer Berlin Heidelberg, Berlin, Heidelberg, 457-460.

[75] Byron Reeves, Annie Lang, Eun Young Kim, and Deborah Tatar. 1999. The effects of screen size and message content on attention and arousal. Media Psychology 1, 1 (1999), 49-67.

[76] Byron Reeves, Matthew Lombard, and Geetu Melwani. 1992. Faces on the screen: Pictures or natural experience. In annual conference of the International Communication Association.

[77] Byron Reeves, Clifford Nass, and Clifford Nass. 2000. Perceptual user interfaces: perceptual bandwidth. Commun. ACM 43, 3 (2000), 65-70.

[78] Byron Reeves and Clifford Ivar Nass. 1996. The media equation: How people treat computers, television, and new media like real people and places. Cambridge University Press, Cambridge, UK.

[79] Barry Reisberg, Emile H Franssen, Liduin EM Souren, Stefanie R Auer, Imran Akram, and Sunnie Kenowsky. 2002. Evidence and mechanisms of retrogenesis in Alzheimer's and other dementias: management and treatment import. American Journal of Alzheimer's Disease \& Other Dementias 17, 4 (2002), 202-212.

[80] Jacob M Rigby, Duncan P Brumby, Anna L Cox, and Sandy JJ Gould. 2016. Watching movies on netflix: investigating the effect of screen size on viewer immersion. In Proceedings of Conference on Human-Computer Interaction with Mobile Devices and Services Adjunct. ACM, New York, NY, USA, 714-721.
[81] Philippa Riley, Norman Alm, and Alan Newell. 2009. An interactive tool to promote musical creativity in people with dementia. Computers in Human Behavior 25, 3 (2009), 599-608.

[82] George Robertson, Mary Czerwinski, Patrick Baudisch, Brian Meyers, Daniel Robbins, Greg Smith, and Desney Tan. 2005. The large-display user experience. IEEE computer graphics and applications 25, 4 (2005), 44-51.

[83] Tom Rodden, Tom Rodden, Andy Crabtree, Terry Hemmings, Boriana Koleva, Jan Humble, Karl-Petter Akesson, and Pär Hansson. 2004. Between the Dazzle of a New Building and Its Eventual Corpse: Assembling the Ubiquitous Home. In Proceedings of Designing Interactive Systems (DIS '04). ACM, New York, NY, USA, 71-80.

[84] Yvonne Rogers, Kay Connelly, Lenore Tedesco, William Hazlewood, Andrew Kurtz, Robert E. Hall, Josh Hursey, and Tammy Toscos. 2007. Why It's Worth the Hassle: The Value of In-situ Studies when Designing Ubicomp. In Proceedings of Conference on Ubiquitous Computing (UbiComp '07). Springer-Verlag, Berlin, Heidelberg, 336-353.

[85] Maxine Saborowski and Ingrid Kollak. 2015. How do you care for technology? Care professionals' experiences with assistive technology in care of the elderly. Technological Forecasting and Social Change 93 (2015), 133-140.

[86] Elizabeth Sanders. 2002. From user-centered to participatory design approaches. Taylor and Francis, London, UK, 1-8.

[87] Vardit Sarne-Fleischmann, Noam Tractinsky, Tzvi Dwolatzky, and Inbal Rief. 2011. Personalized reminiscence therapy for patients with Alzheimer's disease using a computerized system. In Proceedings Pervasive Technologies Related to Assistive Environments. ACM, New York, NY, USA, Article 48, 3 pages.

[88] Corina Sas. 2004. Individual differences in virtual environments. In International conference on computational science. Springer, Berlin, Heidelberg, 1017-1024.

[89] Corina Sas. 2018. Exploring Self-Defining Memories in Old Age and Their Digital Cues. In Proceedings of the 2018 Designing Interactive Systems Conference (DIS '18). ACM, New York, NY, USA, 149-161. DOI : http://dx.doi.org/10.1145/3196709.3196767

[90] Corina Sas, Kieran Brahney, Carl Oechsner, Amish Trivedi, Mauricio Nomesque, Zaffar Mughal, Keith W. Cheverst, Sarah Clinch, and Nigel Davies. 2017. Communication Needs of Elderly at Risk of Falls and Their Remote Family. In Proceedings of Conference Extended Abstracts on Human Factors in Computing Systems (CHI EA'17). ACM, New York, NY, USA, 2900-2908. 
[91] Corina Sas, Scott Challioner, Christopher Clarke, Ross Wilson, Alina Coman, Sarah Clinch, Mike Harding, and Nigel Davies. 2015. Self-defining memory cues: creative expression and emotional meaning. In Proceedings of Conference Extended Abstracts on Human Factors in Computing Systems (CHI EA'15). ACM, New York, NY, USA, 2013-2018.

[92] Corina Sas, Tomasz Fratczak, Matthew Rees, Hans Gellersen, Vaiva Kalnikaite, Alina Coman, and Kristina Höök. 2013. AffectCam: arousal-augmented sensecam for richer recall of episodic memories. In Proceedings of Conference Extended Abstracts on Human Factors in Computing Systems (CHI EA'13). ACM, New York, NY, USA, 1041-1046.

[93] Corina Sas, O’Hare Gregory MP, and Reilly Ronan. 2004. Presence and task performance: an approach in the light of cognitive style. Cognition, Technology \& Work 6 (2004), 53-56. Issue 1.

[94] Corina Sas and Carman Neustaedter. 2017. Exploring DIY practices of complex home technologies. ACM Transactions on Computer-Human Interaction (TOCHI) 24, 2 (2017), 16.

[95] Corina Sas, Shuang Ren, Alina Coman, Sarah Clinch, and Nigel Davies. 2016a. Life Review in End of Life Care: A Practitioner's Perspective. In Proceedings of Conference Extended Abstracts on Human Factors in Computing Systems (CHI EA'16). ACM, New York, NY, USA, 2947-2953.

[96] Corina Sas and Steve Whittaker. 2013. Design for forgetting: disposing of digital possessions after a breakup. In Proceedings of Conference on Human Factors in Computing Systems (CHI'13). ACM, New York, NY, USA, 1823-1832.

[97] Corina Sas, Steve Whittaker, Steven Dow, Jodi Forlizzi, and John Zimmerman. 2014. Generating Implications for Design Through Design Research. In Proceedings of Conference on Human Factors in Computing Systems (CHI '14). ACM, New York, NY, USA, 1971-1980.

[98] Corina Sas, Steve Whittaker, and John Zimmerman. 2016b. Design for rituals of letting go: An embodiment perspective on disposal practices informed by grief therapy. ACM Transactions on Computer-Human Interaction (TOCHI) 23, 4 (2016), 21.

[99] Corina Sas, Karen Wisbach, and Alina Coman. 2017. Craft-based Exploration of Sense of Self. In Proceedings of Conference Extended Abstracts on Human Factors in Computing Systems (CHI EA'17). ACM, New York, NY, USA, 2891-2899.

[100] Dallas P Seitz, Sarah Brisbin, Nathan Herrmann, Mark J Rapoport, Kimberley Wilson, Sudeep S Gill, Jenna Rines, Ken Le Clair, and David Conn. 2012. Efficacy and feasibility of nonpharmacological interventions for neuropsychiatric symptoms of dementia in long term care: a systematic review. Journal of the American Medical Directors Association 13, 6 (2012), 503-506.

[101] Abigail J Sellen, Andrew Fogg, Mike Aitken, Steve Hodges, Carsten Rother, and Ken Wood. 2007. Do life-logging technologies support memory for the past?: an experimental study using Sensecam. In Proceedings of Conference on Human Factors in Computing Systems (CHI'07). ACM, New York, NY, USA, 81-90.

[102] Roger Silverstone. 2005. Domesticating domestication. Reflections on the life of. Open University Press, Maidenhead, UK, 229-248.

[103] Kari Lislerud Smebye, Kirkevold Marit, and Engedal Knut. 2012. How do persons with dementia participate in decision making related to health and daily care? A multi-case study. BMC Health Serv Res. 12, Article 241 (2012), 12 pages.

[104] Aimee Spector, Lene Thorgrimsen, Bob Woods, Lindsay Royan, Steve Davies, Margaret Butterworth, and Martin Orrell. 2003. Efficacy of an evidence-based cognitive stimulation therapy programme for people with dementia: randomised controlled trial. The British Journal of Psychiatry 183, 3 (2003), 248-254.

[105] Molly M Stevens, Gregory D Abowd, Khai N Truong, and Florian Vollmer. 2003. Getting into the Living Memory Box: Family archives \& holistic design. Personal and Ubiquitous Computing 7, 3-4 (2003), 210-216.

[106] O. Storz, A. Friday, N. Davies, J. Finney, C. Sas, and J. Sheridan. 2006. Public Ubiquitous Computing Systems: Lessons from the e-Campus Display Deployments. IEEE Pervasive Computing 5, 3 (July 2006), 40-47.

[107] Benedicte S Strøm, Siri Ytrehus, and Ellen-Karine Grov. 2016. Sensory stimulation for persons with dementia: a review of the literature. Journal of clinical nursing 25, 13-14 (2016), 1805-1834.

[108] Desney S Tan, Darren Gergle, Peter Scupelli, and Randy Pausch. 2003. With similar visual angles, larger displays improve spatial performance. In Proceedings of Conference on Human Factors in Computing Systems (CHI'03). ACM, New York, NY, USA, 217-224.

[109] Desney S Tan, Darren Gergle, Peter G Scupelli, and Randy Pausch. 2004. Physically large displays improve path integration in 3D virtual navigation tasks. In Proceedings of Conference on Human Factors in Computing Systems (CHI'04). ACM, New York, NY, USA, 439-446.

[110] Peter Tolmie and Andy Crabtree. 2008. Deploying Research Technology in the Home. In Proceedings of the 2008 ACM Conference on Computer Supported Cooperative Work (CSCW'08). ACM, New York, NY, USA, 639-648. 
[111] Peter Tolmie, Andy Crabtree, Stefan Egglestone, Jan Humble, Chris Greenhalgh, and Tom Rodden. 2010. Digital Plumbing: The Mundane Work of Deploying UbiComp in the Home. Personal Ubiquitous Comput. 14, 3 (April 2010), 181-196.

[112] Elise van den Hoven and Berry Eggen. 2015. The cue is key. Zeitschrift für Psychologie (2015), 110-117.

[113] Elise Van Den Hoven, Corina Sas, and Steve Whittaker. 2012. Introduction to this special issue on designing for personal memories: past, present, and future. Human-Computer Interaction 27, 1-2 (2012), 1-12.

[114] Joost van Hoof and HSM Kort. 2006. Healthy living environments for older adults with dementia. In HB2006: Proceedings of the 8th International Conference Healthy Buildings, Vol. 3. 89-93.

[115] John Vines, Rachel Clarke, Peter Wright, John McCarthy, and Patrick Olivier. 2013. Configuring Participation: On How We Involve People in Design. In Proceedings of the SIGCHI Conference on Human Factors in Computing Systems (CHI '13). ACM, New York, NY, USA, 429-438. DOI : http://dx.doi.org/10.1145/2470654.2470716

[116] Froukje Sleeswijk Visser, Stappers Pieter Jan, Van der Lugt Remko, and Sanders Elizabeth BN. 2005. Contextmapping: experiences from practice. CoDesign 1 (2005), 119-149. Issue 2.

[117] Jayne Wallace, Anja Thieme, Gavin Wood, Guy Schofield, and Patrick Olivier. 2012. Enabling self, intimacy and a sense of home in dementia: an enquiry into design in a hospital setting. In Proceedings of
Conference on Human Factors in Computing Systems (CHI'12). ACM, New York, NY, USA, 2629-2638.

[118] Jayne Wallace, Peter C Wright, John McCarthy, David Philip Green, James Thomas, and Patrick Olivier. 2013. A design-led inquiry into personhood in dementia. In Proceedings of Conference on Human Factors in Computing Systems (CHI'13). ACM, New York, NY, USA, 2617-2626.

[119] Jenny Waycott, Cosmin Munteanu, Hilary Davis, Anja Thieme, Stacy Branham, Wendy Moncur, Roisin McNaney, and John Vines. 2017. Ethical encounters in HCI: implications for research in sensitive settings. In Proceedings of Extended Abstracts on Human Factors in Computing Systems (CHI EA'17). ACM, New York, NY, USA, 518-525.

[120] Gemma Webster, Deborah I Fels, Gary Gowans, and Vicki L Hanson. 2011. Portraits of individuals with dementia: views of care managers. In Proceedings of the 25th BCS Conference on Human-Computer Interaction. British Computer Society, 331-340.

[121] Mark Weiser. 1991. The Computer for the 21st Century. Scientific American (September 1991).

[122] David West, Aaron Quigley, and Judy Kay. 2007. MEMENTO: a digital-physical scrapbook for memory sharing. Personal and Ubiquitous Computing 11, 4 (2007), 313-328.

[123] Bob Woods, Laura O’Philbin, Emma M. Farrell, Aimee E. Spector, and Martin Orrell. 2018. Reminiscence therapy for dementia. Cochrane database of systematic reviews (2018). Issue 3. 